\title{
PENYELESAIAN SENGKETA ANTARA TENAGA KERJA KONTRAK DENGAN PERUSAHAAN: STUDI KASUS SHERATON BALI KUTA RESORT
}

\author{
Kadek Januarsa Adi Sudharma, Fakultas Hukum dan Ilmu Sosial Universitas \\ Pendidikan Nasional, e-mail: januarsa.adi@undiknas.ac.id \\ Desak Putu Widiati, Fakultas Hukum dan Ilmu Sosial Universitas Pendidikan \\ Nasional, e-mail: desak8892@gmail.com
}

doi: https://doi.org/10.24843/KS.2020.v08.i10.p04

\begin{abstract}
ABSTRAK
Pemutusan hubungan kerja adalah pengakhiran hubungan kerja antara perusahaan atau pekerja, yang disebabkan oleh sejumlah faktor penting. Diatur pada Pasal 62 Undang-Undang Nomor 13 Tahun 2003 tentang Ketenagakerjaan, pihak yang mengakhiri hubungan kerja sebelum berakhirnya jangka waktu yang ditetapkan dalam perjanjian maka pihak yang mengakhiri hubungan kerja tersebut diwajibkan membayar ganti rugi kepada pihak lainnya. Hal inilah yang terjadi di Hotel Sheraton Bali Kuta Resort, dimana salah satu karyawan kontraknya mengundurkan diri sebelum masa kontraknya berakhir. Tujuan penelitian ini adalah untuk mengkaji tentang pertanggungjawaban dan penyelesaian sengketa tenaga kerja kontrak tersebut kepada pihak hotel akibat pengunduran diri sebelum berakhirnya kontrak kerja. Adapun metode penelitian yang digunakan adalah yuridis empiris dengan sifat penelitian deskriptif kualitatif dan mempergunakan data primer berupa hasil wawancara, perjanjian kerja, dan peraturan perusahan pada hotel tersebut dan data sekunder berupa peraturan perundang-undangan dan literature terkait. Hasil penelitiannya adalah bahwa bentuk pertanggungjawaban tersebut adalah kewajiban bagi pihak yang melakukan PHK untuk membayar uang ganti rugi kepada pihak hotel dan penyelesaian sengketa dilakukan melalui jalur non litigasi yakni negoisasi.
\end{abstract}

Kata Kunci: Penyelesaian sengketa, Pekerja Kontrak, Pemutusan Hubungan Kerja

\begin{abstract}
Termination of employment is the termination of employment relations between companies or workers, which is caused by a number of important factors. Regulated in Article 62 of Law Number 13 Year 2003 concerning Manpower, parties who terminate the work relationship before the end of the period stipulated in the agreement, the party terminating the employment relationship is obliged to pay compensation to the other party. This is what happened at the Sheraton Bali Kuta Resort Hotel, where one of his contract employees resigned before his contract period ended. The purpose of this study is to examine the accountability and settlement of disputes for contract workers to the hotel due to resignation before the end of the work contract. The research method used is juridical empirical with the nature of qualitative descriptive research and uses primary data in the form of interviews, work agreements, and company regulations at the hotel and secondary data in the form of statutory regulations and related literature. The result of the research is that this form of accountability is an obligation for the party who carried out the layoffs to pay compensation money to the hotel and dispute resolution is carried out through nonlitigation, namely negotiation.
\end{abstract}

Key Words: Settlement of disputes, Contract Workers, Termination of Employment. 


\section{Pendahuluan}

\subsection{Latar Belakang Masalah}

Undang-Undang Nomor 13 Tahun 2003 tentang Ketenagakerjaan (selanjutnya disebut UU Ketenagakerjaan) merupakan pedoman bagi sistem ketenagakerjaan Indonesia. Hubungan kerja yang mengatur antara pekerja dan pengusaha pada dasarnya memuat hak dan kewajiban dari para pihak ${ }^{1}$. Hak dan kewajiban karyawan dan perusahaan ini tertuang dalam bentuk peraturan perusahaan dan perjanjian kerja. Peraturan perusahaan berisikan pedoman, hak serta kewajiban yang berlaku di perusahaan dan wajib dilaksanakan oleh setiap karyawan. Selain itu aturan yang lebih spesifik yang sifatnya mengikat pada perorangan yaitu perjanjian kerja, yang dalam UU Ketenagakerjaan disebut perjanjian kerja waktu tertentu (PKWT) dan perjanjian kerja untuk waktu tidak tertentu (PKWTT).

Dalam membuat suatu perjanjian kerja perlu diperhatikan bagaimana peranan asas-asas hukum dalam mewujudkan tujuan perjanjian². Salah satu asas dalam perjanjian adalah asas kekuatan mengikat (pacta sunt servanda). Asas kekuatan mengikat kontrak ini mengharuskan para pihak memenuhi apa yang telah merupakan ikatan mereka satu sama lain dalam kontrak yang mereka buat ${ }^{3}$. Berdasarkan asas kekuatan mengikat, maka perjanjian kerja merupakan suatu aturan yang tidak boleh dilanggar oleh pekerja maupun perusahaan karena ada sanksi yang dikenakan.

Suatu perjanjian kerja dapat diadakan untuk waktu tertentu (PKWT) atau untuk waktu tidak tertentu (PKWTT) ${ }^{4}$. PKWT dan PKWTT diatur dalam UU Ketenagakerjaan mulai dari pasal 56. Pasal 56 ayat (2) menyebutkan bahwa PKWT hanya dapat dibuat berdasarkan jangka waktu atau selesainya suatu pekerjaan tertentu. Mengenai isi PKWT disesuaikan berdasarkan ketentuan yang ada di perusahaan seperti halnya jabatan, gaji pokok, besaran bonus, tunjangan, uang makan, uang transport, jam kerja sampai dengan berakhirnya kontrak kerja atau pemutusan hubungan kerja (PHK).

Salah satu permasalahan yang sering muncul dalam hubungan kerja adalah permasalahan PHK $^{5}$, dengan demikian PHK merupakan salah satu hal penting dalam sebuah perjanjian kerja. PHK artinya berakhirnya hubungan kerja antara pekerja dan perusahaan.

Berakhirnya hubungan kerja antara pekerja dengan pengusaha menimbulkan berakhirnya hak dan kewajiban dari masing-masing pihak ${ }^{6}$. Pemutusan hubungan kerja adalah pengakhiran hubungan kerja antara perusahaan atau pekerja, yang disebabkan oleh sejumlah faktor penting7. Berakhirnya hubungan kerja diatur dalam Pasal 61 UU Ketenagakerjaan. Namun yang menarik adalah apabila PHK dilakukan bukan berdasarkan Pasal 61 UU Ketenagakerjaan, maka berdasarkan Pasal 62 UU

1 Suhartoyo, "Perlindungan Hukum Bagi Buruh Dalam Sistem Hukum Ketenagakerjaan Nasional", Administrative Law \& Governance Journal, Universitas Diponegoro 2,No.2,(2019), 328.

2 Sinaga,Niru Anita,"Peranan Asas-Asas Hukum Dalam Perjanjian”, Jurnal Binamulia Hukum, Fakultas Hukum Universitas Dirgantara Marsekal Suryadarma 7,(2018),109.

3 Syaifuddin,M., Hukum Kontrak Memahami Kontrak dalam Perspektif Filsafat, Teori, Dogmatik, dan Praktik Hukum (Seri Pengayan Hukum Perikatan),(Bandung,Mandar Maju,2012,), 91

4 Amalia,Apri, dkk, "Analisis Yuridis Perjanjian Kerja Waktu Tertentu Berdasarkan UndangUndang Ketenagakerjaan dan Hukum Perjanjian”, USU Law Jurnal 5,No. 1(2017), 69.

5 Aisha,Berliana Destrie,"Pemutusan Hubungan Kerja Yang Didasarkan Pada Pelanggaran Perjanjian Kerja Bersama", Jurnal Jurist-Diction Universitas Airlangga 2,No.1,(2019),65.

6 Soedarjadi,Hak dan Kewajiban Pekerja-Pengusaha,(Yogyakarta,Pustaka Yustisia,2009),83

7 Simanjuntak,Danny, PHK dan Pesangon Karyawan ,(Jakarta, Visi Media,2007),18. 
Ketenagakerjaan, pihak yang mengakhiri hubungan kerja sebelum berakhirnya jangka waktu yang ditetapkan dalam perjanjian maka pihak yang mengakhiri hubungan kerja tersebut diwajibkan membayar ganti rugi kepada pihak lainnya.

Hal inilah yang terjadi di salah satu hotel di Bali yaitu Sheraton Bali Kuta Resort (selanjutnya disebut SBKR). Salah satu karyawan kontrak SBKR yaitu Anton (nama disamarkan) mengundurkan diri sebelum masa kontraknya berakhir. Berdasarkan Pasal 62 UU Ketenagakerjaan, maka Anton wajib membayar ganti rugi kepada SBKR sebesar gaji yang diterima Anton sampai batas waktu berakhirnya kontrak kerja Anton. Akan tetapi dalam hal ini Anton merasa tidak sanggup untuk membayar sejumlah uang tersebut karena dianggap terlalu besar bagi Anton.

Karyawan kontrak di SBKR dapat dikatakan lalai atau bahkan tidak mengetahui tentang adanya Pasal 62 UU Ketenagakerjaan. Sebaliknya, hal ini juga bisa terjadi akibat dari lemahnya standar operasional dan prosedur SBKR dalam membina karyawan baru khususnya karyawan kontrak. Dengan adanya kasus yang terjadi di SBKR, maka diperlukan kajian analisis mengenai pertanggungjawaban serta penyelesaian sengketa yang terjadi terkait ganti rugi yang diwajibkan kepada karyawan kontrak SBKR sehingga dapat ditemukan akar dari permasalahan serta bagaimana bekerjanya UU Ketenagakerjaan dalam masyarakat, terutama kalangan pekerja.

\subsection{Rumusan Masalah}

Adapun rumusan masalah yang akan diangkat dalam penelitian ini adalah :

1. Bagaimanakah pertanggungjawaban tenaga kerja kontrak kepada perusahaan akibat pengunduran diri sebelum berakhirnya kontrak kerja di Sheraton Bali Kuta Resort?

2. Bagaimanakah penyelesaian sengketa antara tenaga kerja kontrak dengan perusahaan akibat pengunduran diri sebelum berakhirnya kontrak kerja di Sheraton Bali Kuta Resort?

\subsection{Tujuan Penulisan}

Berdasarkan pada rumusan masalah di atas, maka tujuan dari penelitian ini untuk mengkaji tentang pertanggungjawaban tenaga kerja kontrak tersebut kepada SBKR akibat pengunduran diri sebelum berakhirnya kontrak kerja serta untuk mengkaji tentang penyelesaian sengketa tenaga kerja kontrak dan perusahaan akibat pengunduran diri sebelum berakhirnya kontrak kerja di SBKR.

\section{Metode Penelitian}

Penelitian ini adalah penelitian yuridis empiris yang dilaksanakan pada tahun 2019 dengan sifat penelitian deskriptif kualitatif dan mempergunakan data primer dan data sekunder. Data yang diperoleh dalam penelitian ini didapatkan dengan teknik wawancara dan studi dokumen. Adapun data primer terdiri dari hasil wawancara dengan human resources department (HRD) SBKR, perjanjian kerja SBKR dan peraturan perusahan SBKR sedangkan data sekunder yang digunakan terdiri dari bahan hukum primer yaitu berupa perundang-undangan yang terkait dengan ketenagakerjaan, bahan hukum sekunder berupa buku-buku dan jurnal yanng berkaitan dengan ketenagakerjaan dan bahan hukum sekunder berupa internet. Penelitian dimulai dengan mencocokan data yang didapatkan dari hasil wawancara dengan perjanjian kerja, peraturan perusahaan dan arsip / dokumen lainnya serta mencocokan hasil wawancara antara $H R D$, Anton yang merupakan tenaga kerja kontrak SKBR yang 
mengundurkan diri sebelum kontrak berakhir untuk memastikan keakuratan data yang didapatkan. Data-data tersebut kemudian dianalisis menggunakan teori hukum serta perundang-undangan yang digunakan sebagai acuan dalam penelitian ini.

\section{Hasil dan Pembahasan}

\subsection{Pertanggungjawaban Tenaga Kerja Kontrak Kepada Perusahaan Akibat} Pengunduran Diri Sebelum Berakhirnya Kontrak Kerja di Sheraton Bali Kuta Resort

SBKR merupakan hotel yang terletak di Beachwalk Shopping Center di jalan Pantai Kuta Bali yang merupakan milik dari PT. Indonesian Paradise Island dan dikelola oleh salah satu manajemen yaitu Marriott International. Berdasarkan Hasil wawancara dengan Sinta Kusumantari, Director of Human Resources, hotel ini sudah mulai beroperasi sejak 1 Desember $2012^{8}$. Adapun jumlah karyawan per tahun 2019, berdasarkan perolehan data adalah sebagai berikut:

\begin{tabular}{|l|c|}
\hline \multicolumn{1}{|c|}{ Status Karyawan } & Jumlah \\
\hline Staff & 217 \\
\hline Non Staff (Trainee) & 79 \\
\hline Outsourcing & 36 \\
\hline Daily Worker & 87 \\
\hline Total Karyawan & $\mathbf{4 1 9}$ \\
\hline Sumber : Director of Human Resources of Sheraton Bali Kuta Resort, Tahun 2019 \\
\hline
\end{tabular}

Berdasarkan tabel diatas, karyawan SBKR hingga tahun 2019 berjumlah 419 orang karyawan. Jumlah tersebut sudah termasuk diantaranya karyawan tetap sebanyak 217 orang, karyawan trainee (karyawan kontrak) sebanyak 79 orang, karyawan outsourcing sebanyak 36 orang, dan karyawan harian (daily worker) sebanyak 87 orang. Karyawan tetap merupakan karyawan yang telah diangkat oleh SBKR untuk menjadi karyawan tetap, di mana dalam UU Ketenagakerjaan dikatakan sebagai PKWTT sedangkan karyawan trainee (karyawan kontrak) merupakan karyawan yang terikat perjanjian kerja dengan SBKR dengan jangka waktu tertentu, di mana dalam UU Ketenagakerjaan hal ini disebut sebagai PKWT. Dalam hukum ketenagakerjaan, jenis perjanjian kerja dibedakan menjadi :

1) Perjanjian kerja untuk waktu tertentu (PKWT), yaitu perjanjian kerja antara pekerja/buruh dengan pengusaha untuk mengadakan hubungan kerja dalam waktu tertentu atau untuk pekerjaan tertentu.

2) Perjanjian kerja untuk waktu tidak tertentu (PKWTT), yaitu perjanjian kerja antara pekerja atau buruh dengan pengusaha untuk mengadakan hubungan kerja tetap ${ }^{9}$.

Perjanjian kerja waktu tertentu (PKWT) dibagi menjadi 2 yaitu :

1) PKWT didasarkan atas jangka waktu, yang diatur dalam Pasal 59 ayat (3) UU Ketenagakerjaan.

8 Hasil wawancara dengan Sinta Kusumantari, Director of Human Resources, tanggal 25 Desember 2019, bertempat di Hotel Sheraton Bali Kuta Resort.

9 Shalihah,Fithriatus,"Implementasi Perjanjian Kerja Waktu Tertentu (PKWT) Dalam Hubungan Kerja di Indonesia", Jurnal Selat, Fakultas Hukum Universitas Riau 4, No. 1 (2016), 75 . 
2) PKWT yang didasarkan jenis pekerjaan tertentu, yang diatur dalam Pasal 59 ayat (1) UU Ketenagakerjaan ${ }^{10}$.

Tujuan dari pada perjanjian kerja adalah untuk mencapai stabilitas di dalam syarat-syarat kerja ${ }^{11}$. Dalam peraturan perusahaan SBKR apabila karyawan kontrak telah menjalani kontrak kerja dengan SBKR selama 2 (dua) tahun, maka karyawan tersebut akan diangkat menjadi karyawan tetap oleh SBKR. Hal ini sesuai dengan amanat UU Ketenagakerjaan pasal 59 ayat (4) yaitu PKWT hanya dapat dilaksanakan paling lama 2 (dua) tahun dan hanya dapat diperpanjang 1 (satu) kali12.

PKWT yang dibuat oleh SBKR memuat berbagai hal, salah satunya mengenai PHK. Dalam perjanjian tersebut disebutkan bahwa PHK mengacu pada Pasal 62 UU Ketenagakerjaan. PHK dalam teori hukum perburuhan dibagi menjadi 4 jenis :

a. Pemutusan hubungan kerja demi hukum

b. Pemutusan hubungan kerja oleh pekerja

c. Pemutusan hubungan kerja oleh pengusaha

d. Pemutusan hubungan kerja oleh pengadilan ${ }^{13}$.

Pemutusan hubungan kerja oleh pekerja/buruh disebabkan oleh dua hal :

a. Karena permintaan pengunduran diri

b. Karena permohonan PHK Kepada pengadilan Hubungan Industrial.

Secara hukum dan dalam praktiknya PHK tidak hanya dominan dilakukan oleh pengusaha, tetapi juga dapat dilakukan oleh pekerja/buruh. Dalam hal pemutusan hubungan kerja oleh pekerja/buruh atas permintaan pengunduran diri yaitu PHK tersebut timbul karena kehendak pekerja/buruh secara murni tanpa adanya rekayasa pihak lain ${ }^{14}$.

Suatu kontrak kerja adalah juga berlaku sebagaimana perjanjian biasa. Ia menimbulkan prestasi (kewajiban) yang harus dipenuhi oleh kedua belah pihak ${ }^{15}$. Permasalahan yang terjadi ketika Anton salah satu pegawai kontrak SBKR mengundurkan diri ditengah-tengah masa kontraknya. Awalnya Anton dikontrak selama 1 (satu) tahun oleh SBKR untuk mengisi posisi sebagai sebagai Sous Chef, Pastry / Bakery, kemudian setelah masa kontrak selesai, Anton dan SBKR sepakat untuk memperpanjang kembali kontrak tersebut selama 1 (tahun), sehingga Anton sedang menjalani kontrak keduanya di SBKR. Kontrak kedua Anton dimulai dari 14 April 2018 dan akan berakhir pada 13 Maret 2019. Berdasarkan hasil wawancara dengan Anton, tanggal 20 April 2020, setelah bekerja selama 5 (lima) bulan pada masa kontrak kerjanya yang kedua tersebut, Anton mengajukan pengunduran diri tepatnya pada

10 Amalia,Apri, dkk, Op.Cit, 68.

11 Maulinda,Rizqa,dkk,"Perlindungan Hukum Bagi Pekerja Kontrak Waktu Tertentu Dalam Perjanjian Kerja Pada PT. Indotruck Utama", Kanun Jurnal Ilmu Hukum 18, No. 3 (2016), 339.

12 Rosita, Ita,T. N. Hamsyah, "Perlindungan Hukum Terhadap Tenaga Kerja Dalam Perjanjian Kerja Waktu Tertentu Pada Perusahaan Garmen”, Jurnal Living Law Universitas Djuanda 8, No. 2 (2016), h. 116.

13 Asyhadie,Zaeni, "Dasar-Dasar Hukum Perburuhan (Pemutusan Hubungan Kerja)”, (Jakarta, Raja Grafindo Persada,2002), h. 140.

14 Khakim,Abdul, "Pengantar Hukum Ketenagakerjaan Indonesia",(Bandung, Citra Aditya Bakti, 2003), h.189.

15 Eriza,Novi, "Tanggung Jawab Ganti Rugi Atas Pemutusan Kontrak Kerja Sepihak Terhadap Pekerja Oleh PT. Sucofindo Episi Kota Pekanbaru Berdasarkan Undang-Undang Nomor 13 Tahun 2003 Tentang Ketenagakerjaan", JOM Fakultas Hukum 3, No.2, (2016), h.6. 
bulan Juli 201816. Menurut Peraturan Perusahaan Sheraton Bali Kuta Resort Tahun 2018-2020 BAB XIII tentang Berakhirnya Hubungan Kerja Pasal 52.3 mengatur bahwa : "Putusnya hubungan kerja antara perusahaan dengan pekerja tanpa perlu penetapan dari Pengadilan Penyelesaian Perselisihan Hubungan Industrial (PPHI) dapat diakibatkan hal-hal berikut :

a) PHK karena pekerja meninggal dunia.

b) PHK karena pekerja mengundurkan diri.

c) PHK dalam masa percobaan.

d) PHK karena pekerja mencapai usia pensiun.

e) PHK karena pekerja dinyatakan terlibat tindak kriminall oleh Pengadilan Negara karena tingkah lakunya di luar pekerjaan/ hotel dan/atau lingkungan dalam hotel.

f) PHK karena berakhirnya Perjanjian Kerja Waktu Tertentu."17

Berdasarkan pasal di atas, maka Anton termasuk dalam poin b, di mana putusnya hubungan kerja antara Anton dan SBKR diakibatkan oleh pengunduran diri oleh Anton, sehingga Anton adalah pihak yang mengakhiri hubungan kerja dengan SBKR. Mengenai PHK dalam perjanjian kerja SBKR juga telah jelas dicantumkan bahwa PHK mengacu pula pada UU Ketenagakerjaan, Bab IX, Pasal 62 di mana pasal tersebut menyebutkan bahwa:

"Apabila salah satu pihak mengakhiri hubungan kerja sebelum berakhirnya jangka waktut yang ditetapkan dalam perjanjian kerja waktu tertentu, atau berakhirnya hubungan kerja bukan karena ketentuan sebagaimana dimaksud dalam Pasal 61 ayat (1), pihak yang mengakhiri hubungan kerja diwajibkan membayar ganti rugi kepada pihak lainnya sebesar upah pekerja/buruh sampai batas waktu berakhirnya jangka waktu perjanjian kerja."

Hasil wawancara dengan salah satu karyawan kontrak SBKR pada tanggal 25 Desember 2019, Hari Indrajaya, mengatakan bahwa pada saat penandatanganan kontrak kerja, dia diberikan waktu beberapa saat untuk membaca seluruh isi perjanjian kerja dan menanyakan apabila ada isi perjanjian yang kurang jelas atau tidak dipahami sebelum ditandatangani. ${ }^{18}$

Menurut Abdulkadir Muhammad, teori tanggung jawab dalam perbuatan melanggar hukum (tort liability) dibagi menjadi beberapa teori, yaitu :

a) Tanggung jawab akibat perbuatan melanggar hukum yang dilakukan dengan sengaja (intertional tort liability), tergugat harus sudah melakukan perbuatan sedemikian rupa sehingga merugikan penggugat atau mengetahui bahwa apa yang dilakukan tergugat akan mengakibatkan kerugian.

b) Tanggung jawab akibat perbuatan melanggar hukum yang dilakukan karena kelalaian (negligence tort liability), didasarkan pada konsep kesalahan (concept of fault) yang berkaitan dengan moral dan hukum yang sudah bercampur baur (interminglend).

16 Hasil wawancara dengan Anton, tanggal 20 April 2020 melalui media telekomunikasi.

17 Peraturan Perusahaan Sheraton Bali Kuta Resort Tahun 2018-2020, h. 54.

18 Hasil wawancara dengan Hari Indrajaya, Karyawan kontrak / Finance, 25 Desember 2019 bertempat di hotel Sheraton Bali Kuta Resort. 
c) Tanggung jawab mutlak akibat perbuatan melanggar hukum tanpa mempersoalkan kesalahan (strick liability), didasarkan pada perbuatannya baik secara sengaja maupun tidak sengaja, artinya meskipun bukan kesalahannya tetap bertanggung jawab atas kerugian yang timbul akibat perbuatannya ${ }^{19}$.

Berdasarkan teori oleh Abdulkadir Muhammad di atas, maka Anton termasuk dalam poin a, tanggung jawab akibat perbuatan melanggar hukum yang dilakukan dengan sengaja (intertional tort liability). Artinya, Anton dengan sengaja melakukan pengunduran diri untuk mengakhiri hubungan kerja dengan SBKR, sehingga Anton harus membayar ganti rugi kepada SBKR.

Pihak yang mengakhiri hubungan kerja diwajibkan membayar ganti rugi kepada pihak lainnya sebesar upah pekerja/buruh sampai batas waktu berakhirnya jangka waktu perjanjian kerja (Pasal 62 UU Ketenagakerjaan), dengan demikian Anton seharusnya membayar kepada pihak Sheraton Bali Kuta Resort sebesar Rp. 46.612.500,(empat puluh enam juta enam ratus dua belas ribu lima ratus rupiah). Adapun bentuk perhitungan ganti rugi tersebut sebagai berikut :

\begin{tabular}{|c|c|c|c|c|c|}
\hline \multicolumn{6}{|c|}{ Sheraton Bali Kuta Resort } \\
\hline \multicolumn{6}{|c|}{ Final Payment } \\
\hline \multicolumn{6}{|c|}{ Obligation to pay the rest of working contract period } \\
\hline Due Date & & March 12th, 2019 & Start Calculation & & August 3rd, 2018 \\
\hline \multicolumn{6}{|c|}{ Employee Detail } \\
\hline Employee Name : & \multicolumn{2}{|l|}{ Anton } & Departement: & \multicolumn{2}{|l|}{ FBK } \\
\hline Position : & \multicolumn{2}{|l|}{ Sous Chef, Pastry/Bakery } & Reason: & \multicolumn{2}{|l|}{ Resignation } \\
\hline Commencing Date : & \multicolumn{2}{|l|}{ March 13th, 2017} & Years of Service : & \multicolumn{2}{|l|}{$1 Y, 5 \mathrm{M}$} \\
\hline Status : & \multicolumn{2}{|l|}{ 2nd Contract } & & & \\
\hline \multicolumn{3}{|l|}{ Salary and Benefits } & \multicolumn{3}{|l|}{ Term/Sifat Tunjangan } \\
\hline \multicolumn{2}{|l|}{ Basic Salary : } & 6.393 .750 & \multicolumn{3}{|l|}{ Fix / Tetap } \\
\hline \multicolumn{2}{|l|}{ Meal \& Transport / day : } & - & \multicolumn{3}{|l|}{ Not Fix / Tidak Tetap } \\
\hline \multicolumn{2}{|l|}{ Tunjangan Jabatan : } & - & \multicolumn{3}{|l|}{ Fix / Tetap } \\
\hline \multicolumn{2}{|l|}{ Allowance 15th Years Service : } & - & \multicolumn{3}{|l|}{ Fix / Tetap } \\
\hline \multicolumn{2}{|l|}{ Total Fix salary : } & - & & & \\
\hline \multicolumn{6}{|l|}{ Legal Basic } \\
\hline \multicolumn{6}{|c|}{ Article 62 - Labor Laws No. 13 Years 2003 as below : } \\
\hline \multicolumn{6}{|l|}{ Payroll Date Every Month on 25th } \\
\hline \multirow[t]{11}{*}{ Proposional August Penalties } & 04 Aug -31 Aug $2018=27$ Days & & Prorate Salary: 27 Days & & 5.568 .750 \\
\hline & 01 Sep -30 Sep $2018=30$ Days & & Full Salary & & 6.393 .750 \\
\hline & 01 Oct -31 Oct 2018 = 31 Days & & Full Salary & & 6.393 .750 \\
\hline & 01 Nov -30 Nov 2018 = 30 Days & & Full Salary & & 6.393 .750 \\
\hline & 01 Dec -31 Dec $2018=31$ Days & & Full Salary & & 6.393 .750 \\
\hline & $01 \mathrm{Jan}-31 \mathrm{Jan} 2019$ = 31 Days & & Full Salary & & 6.393 .750 \\
\hline & $01 \mathrm{Feb}-28 \mathrm{Feb} 2019=28$ Days & & Full Salary & & 6.393 .750 \\
\hline & $01 \mathrm{Mar}-13 \mathrm{Mar} 2019=13$ Days & & Prorate Salary : 13 Days & & 2.681 .250 \\
\hline & \multicolumn{2}{|l|}{ Pro-rata Religious Allowance } & & & \\
\hline & \multirow{2}{*}{\multicolumn{2}{|c|}{ Meal \& Transport Allowance }} & & & \\
\hline & & & Total & & 46.612 .500 \\
\hline
\end{tabular}

Sumber : Arsip Human Resources Sheraton Bali Kuta Resort

Berdasarkan data diatas dapat dijelaskan bahwa tanggal Anton mulai bekerja di SBKR adalah tanggal 13 Maret 2017. Dalam menjalankan kontrak kedua Anton hanya bekerja dari 13 Maret 2018 sampai 3 Agustus 2018, sehingga perhitungan ganti rugi mulai terhitung sejak tanggal 4 Agustus 2018 sampai dengan 13 Maret 2019 atau selama 8 (delapan) bulan. Besaran ganti rugi yang dibebankan kepada Anton berdasarkan Pasal 62 UU Ketenagakerjaan yaitu didasarkan pada gaji pokok. Gaji pokok Anton sesuai dengan perjanjian adalah sebesar Rp. 6.393.750,- (enam juta tiga ratus sembilan puluh tiga ribu tujuh ratus lima puluh rupiah). Untuk bulan Agustus

19 Muhammad,Abdulkadir,Hukum Perusahaan Indonesia,(Bandung, Citra Aditya Bakti, 2010), 503. 
2018 besaran ganti ruginya adalah Rp. 5.568.750,- (lima juta lima ratus enam puluh delapan ribu tujuh ratus lima puluh rupiah). Ganti rugi pada bulan Maret 2019 terhitung mulai tanggal 1 sampai 13 Maret 2019 yaitu sebesar Rp. 2.681.250,- (dua juta enam ratus delapan puluh satu ribu dua ratus lima puluh rupiah). Dengan demikian maka perhitungan ganti rugi selama 8 (delapan) bulan tersebut adalah sebesar Rp. 5.568.750,- (lima juta lima ratus enam puluh delapan ribu tujuh ratus lima puluh rupiah) pada bulan pertama, kemudian Rp. 6.393.750,- (enam juta tiga ratus sembilan puluh tiga ribu tujuh ratus lima puluh rupiah) pada bulan ke 2 (dua) hingga bulan ke 7 (tujuh) dan Rp. 2.681.250,- (dua juta enam ratus delapan puluh satu ribu dua ratus lima puluh rupiah) pada bulan ke delapan atau bulan terakhir, sehingga total besaran ganti kerugian selama delapan bulan adalah sebesar Rp. 46.612.500,- (empat puluh enam juta enam ratus dua belas ribu lima ratus rupiah).

Pengunduran diri Anton juga memberikan kerugian pada SBKR salah satunya adalah posisi sous chef menjadi kosong dan kekosongan posisi atau jabatan tersebut berdampak kepada berbagai hal terutama yang menyangkut soal pastry/bakery. Beberapa job desk menjadi tidak dapat terlaksana. Terlebih lagi belum ada pengganti yang diperoleh oleh SBKR untuk mengisi posisi tersebut ${ }^{20}$. Pemberian sanksi kepada Anton juga memberikan manfaat bagi Sheraton Bali Kuta Resort. Utilitarianisme adalah suatu teori yang menyatakan bahwa suatu tindakan yang patut adalah memaksimalkan kebahagiaan dan mengurangi penderitaan dan bahwa yang baik adalah yang berguna, bermanfaat dan berfaedah, sebaliknya yang jahat atau buruk adalah yang tidak bermanfaat, tidak berfaedah dan merugikan ${ }^{21}$. Berdasarkan teori ini, tindakan yang patut adalah tindakan tersebut haruslah membawa kebahagiaan dan membawa manfaat. Penganut utilistis ini menganggap bahwa tujuan dari hukum semata-mata untuk memberikan kemanfaatan atau kebahagiaan yang sebesarbesarnya bagi sebanyak-banyaknya masyarakat ${ }^{22}$. Berdasarkan hal tersebut tujuan dari hukum itu sendiri adalah untuk memberikan manfaat kepada sebanyak-banyaknya masyarakat yang jika dikaitkan dengan kasus Anton, hukum yang dimaksud dalam kasus ini adalah perjanjian kerja yang ditandatangani oleh Anton karena perjanjian merupakan undang-undang bagi mereka yang mengikatkan dirinya (pacta sunt servanda).

Tujuan dari pemberian sanksi terhadap pelanggaran yang dilakukan Anton adalah untuk memberikan manfaat kepada sebanyak-banyaknya karyawannya bukan masyarakat umum karena kasus ini merupakan kasus internal antara SBKR dengan Anton sebagai karyawannya, sehingga manfaat tersebut ditujukan untuk kesejahteraan karyawan SBKR. Uang yang diberikan Anton sebagai bentuk ganti rugi tentunya bermanfaat sebagai pemasukan tambahan yang mempengaruhi besaran bonus yang diterima oleh seluruh karyawan bersamaan dengan gaji bulanan. Semakin besar bonus bulanan yang dicapai oleh SBKR, maka semakin besar pula total pendapatan bulanan setiap karyawan SBKR, begitupun sebaliknya. Lebih lanjut hasil wawancara dengan Sinta Kusumantari, uang ganti rugi tersebut dimaksudkan untuk menjadi modal awal

20 Hasil wawancara dengan Sinta Kusumantari, Director of Human Resources, tanggal 25 Desember 2019, bertempat di Hotel Sheraton Bali Kuta Resort.

21 Utilitarianisme, https://business-law.binus.ac.id/2016/06/30/utilitarianisme-dan-tujuanperkembangan-hukum-multimedia-diindonesia/\#: :text=Teori\%20utilitarianisme\%20yang\%20digagas\%20oleh,tidak\%20kabur\%2 0dan\%20tidak\%20tetap. , diakses bulan Januari 2020.

22 Ali,Achmad, Menguak Teori Hukum dan Teori Peradilan, (Jakarta, Prenadamedia Group,2009), 272. 
mencetak karyawan baru untuk menggantikan Anton, dan berdasarkan Peraturan Perusahaan SBKR, uang tersebut juga digunakan untuk menyiapkan seragam, membayar biaya pelatihan khusus dan berbagai hal lainnya untuk keperluan karyawan pengganti Anton ${ }^{23}$.

\subsection{Penyelesaian Sengketa Antara Tenaga Kerja Kontrak Dengan Perusahaan Akibat Pengunduran Diri Sebelum Berakhirnya Kontrak Kerja di Sheraton Bali Kuta Resort.}

Peraturan perusahaan SBKR Tahun 2018 - 2020 pada BAB XIV tentang Penanganan dan Penyelesaian Keluhan Pekerja, Pasal 58 tentang Tata Cara Penyelesaian Keluhan telah mengatur mengenai penyelesaian sengketa atau keluhan dari karyawan, yaitu sebagai berikut :

1. Berdasarkan prinsip yang terdapat dalam Hubungan Industrial, merupakan kewajiban manajemen untuk menyelesaikan kesalahan pekerja dengan efektif.

2. Penyelesaian keluhan dari pekerja karena pekerja merasa diperlakukan tidak wajar, tidak adil, atau bertentangan dengan peraturan perusahaan yang berlaku, pekerja harus mengikuti tata cara sebagai berikut :

a) Pertama kali pekerja harus membicarakan dan menyelesaikan bersama dengan atasan langsung yang berwenang dalam waktu 48 (empat puluh delapan) jam.

b) Keluhan yang tidak dapat diselesaikan oleh atasan langsung dalam waktu 3 (tiga) hari kerja akan dibicarakan pada level kepala bagian.

c) Apabila sudah 3 (tiga) hari kerja, masalah tersebut belum juga dapat diselesaikan, maka harus dijajukan kepada bagian Sumber Daya Manusia untuk dicari penyelesaiannya dalam waktu 5 (lima) hari kerja.

d) Jika kesepakatan tidak tercapai, masalah akan diajukan kepada General Manager / yang mewakilinya yang akan mengambil keputusan akhir. Sedapat mungkin setiap keluhan akan dicarikan penyelesaian secara internal sebelum melibatkan pihak ketiga.

e) Hanya keluhan atau pertikaian yang benar-benar masih tetap belum dapat diselesaikan secara internal yang dapat dimintakan bantuan penyelesaian Kepala Dinas Sosial dan Tenaga Kerja setempat sesuai peraturan pemerintah yang berlaku ${ }^{24}$.

Peraturan perusahaan tersebut dengan jelas mensyaratkan bahwa setiap perselisihan, pertikaian, ataupun keluhan karyawan akan diselesaikan secara internal terlebih dahulu sebelum melibatkan pihak ketiga ${ }^{25}$.

Proses alternatif penyelesaian sengketa yang lebih fleksibel dibandingkan dengan beracara di pengadilan lebih memiliki kemampuan untuk menghasilkan kesepakatan yang mencerminkan kepentingan dan kebutuhan para pihak. Para pihak yang bersengketa dapat duduk secara bersama-sama, merumuskan jalan keluar untuk dapat

23 Hasil wawancara dengan Sinta Kusumantari, Director of Human Resources, tanggal 25 Desember 2019, bertempat di Hotel Sheraton Bali Kuta Resort.

24 Peraturan Perusahaan SBKR, Op.Cit. Hal 61

25 Hasil wawancara dengan Hari Indrajaya, Karyawan kontrak / Finance, 25 Desember 2019 bertempat di hotel Sheraton Bali Kuta Resort. 
menyelesaikan permasalahan yang ada. Jalan keluar yang dipilih merupakan hasil kesepakatan kedua belah pihak yang sedang bersengketa ${ }^{26}$.

Berdasarkan hasil wawancara dengan Anton, sejalan dengan konsep penyelesaian sengketa berdasarkan Undang-Undang Nomor 30 Tahun 1999 (selanjutnya disebut UU APS), sengketa antara Anton dan SBKR dilakukan dengan menempuh jalur negosiasi oleh Anton dengan bagian Human Resources melalui surat elektronik (email) ${ }^{27}$.

Dalam email tersebut Anton mengaku tidak sanggup membayar penuh ganti kerugian yang diberikan kepadanya dan menegosiasikan besaran ganti rugi agar dapat diringankan menjadi seperempat dari total keseluruhan ganti rugi. Menanggapi negosiasi dari Anton, maka pihak Human Resources bekerja sama dengan bagian Finance, merundingkan hal tersebut dengan General Manager. Setelah mendapatkan persetujuan dari General Manager bahwa permintaan negosiasi Anton dikabulkan yaitu kemudian bagian Finance memberikan perincian pembayaran ganti rugi yang baru kepada bagian Human Resources untuk diinformasikan kembali kepada Anton ${ }^{28}$. Adapun rincian ganti rugi setelah negosiasi yang diberikan $H R D$ kepada Anton adalah sebagai berikut :

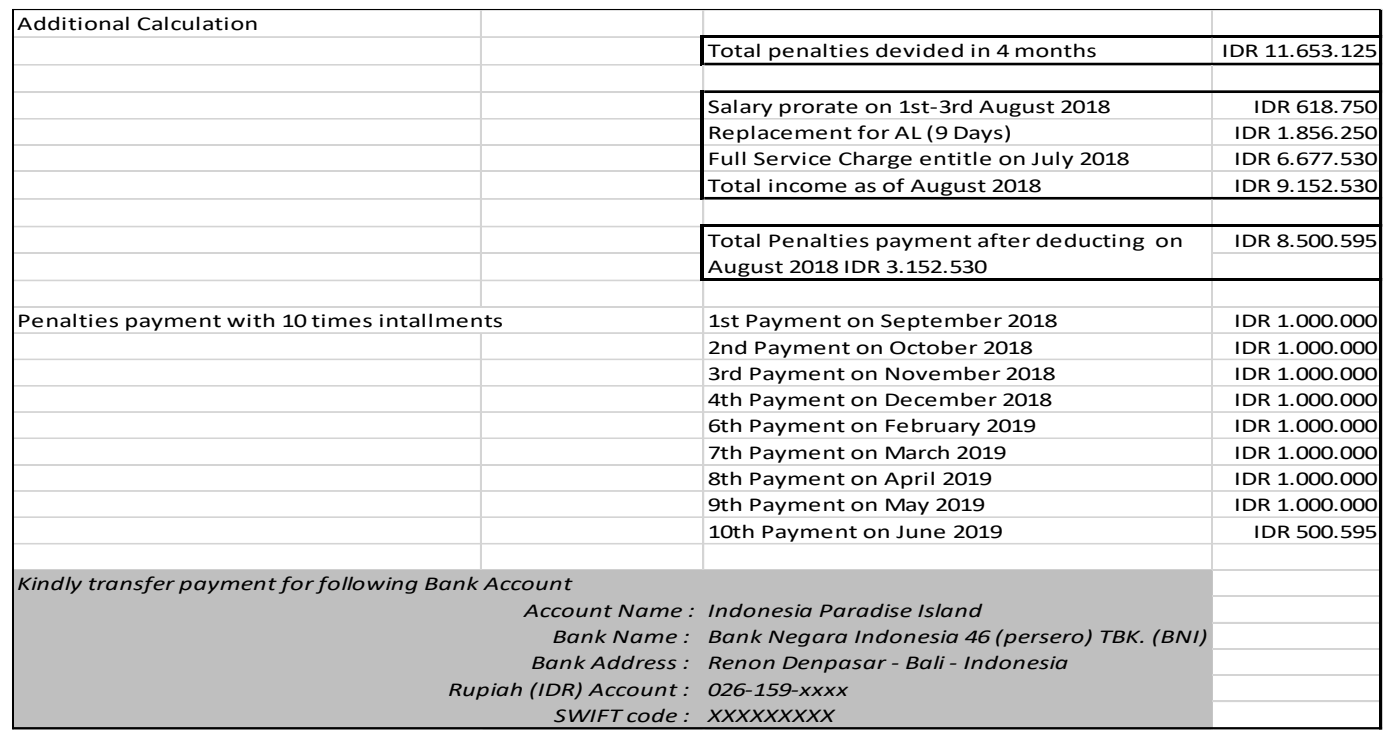

Sumber : Arsip Human Resources Sheraton Bali Kuta Resort

Total ganti rugi yang diberikan setelah negosiasi adalah sebesar Rp. 11.653.125 (sebelas juta enam ratus lima puluh tiga seratus dua puluh lima rupiah) dengan jangka waktu pelunasan ganti rugi selama 10 (sepuluh) bulan dengan cara di cicil setiap bulan. Cicilan dimulai dari bulan Agustus 2018 dengan cicilan awal sebesar Rp. 3.152.530,- (tiga juta seratus lima puluh dua ribu lima ratus tiga pulluh rupiah), kemudian sisanya sebesar Rp. 8.600.595,- (delapan juta enam ratus ribu lima ratus sembilan puluh lima rupiah) dicicil mulai bulan September 2018 sampai dengan bulan

26 Yuniarti,Rahmi, "Efisiensi Pemilihan Alternatif Penyelesaian Sengketa Dalam Penyelesaian Sengketa Waralaba", Fiat Justitia Journal of Law Fakultas Hukum Universitas Lampung 10, No.3 (2016), h.560.

27 Hasil wawancara dengan Anton, tanggal 20 April 2020 melalui media telekomunikasi..

28 Hasil wawancara dengan Sinta Kusumantari, Director of Human Resources, tanggal 25 Desember 2019, bertempat di Hotel Sheraton Bali Kuta Resort. 
Mei 2019 sebesar Rp. 1.000.000,- (satu juta rupiah) untuk setiap bulannya, dan pembayaran terkahir di bulan Juni 2019 sebesar Rp. 500.595,- (lima ratus ribu lima ratus sembilan puluh lima rupiah). Nominal tersebut disetujui pula oleh Anton, kemudian Anton memberikan nomor kartu kreditnya sebagai jaminan untuk membayar. Hasil negosiasi beserta rincian pembayaran ganti rugi dikirimkan ke Anton dan ditandatangani oleh Anton dengan materai Rp. 6.000,- (enam ribu rupiah). Selain itu ditandatangani oleh Director of Human Resources, Asst. HR Manager, dan Director of Finance, kemudian dijadikan arsip oleh bagian Human Resources dan salinannya diberikan juga kepada Anton ${ }^{29}$.

\section{Kesimpulan}

Berdasarkan hasil penelitian maka dapat ditarik kesimpulan sebagai berikut: bentuk pertanggungjawaban Anton sebagai karyawan kontrak kepada SBKR menurut teori pertanggungjawaban hukum adalah dengan diterimanya sanksi oleh Anton berdasarkan Pasal 62 UU Ketenagakerjaan dan perjanjian kerja yang telah disepakati bersama yaiu dengan membayar ganti kerugian, kemudian uang tersebut digunakan semaksimal mungkin untuk kesejahteraan seluruh karyawan dan untuk perekrutan karyawan baru. Penyelesaian sengketa dilakukan sesuai dengan Peraturan perusahaan SBKR Tahun 2018 2020 pada BAB XIV tentang Penanganan dan Penyelesaian Keluhan Pekerja, Pasal 58 tentang Tata Cara Penyelesaian Keluhan telah mengatur mengenai penyelesaian sengketa atau keluhan dari karyawan. Ganti rugi yang dibebankan kepada Anton diselesaikan dengan cara negosiasi antara Anton dan pihak Sheraton Bali Kuta Resort.

\section{DAFTAR PUSTAKA}

\section{Buku:}

Ali,Achmad, Menguak Teori Hukum dan Teori Peradilan, (Jakarta, Prenadamedia Group,2009).

Asyhadie,Zaeni, "Dasar-Dasar Hukum Perburuhan (Pemutusan Hubungan Kerja)", (Jakarta, Raja Grafindo Persada,2002).

Khakim,Abdul, "Pengantar Hukum Ketenagakerjaan Indonesia",(Bandung, Citra Aditya Bakti, 2003).

Muhammad,Abdulkadir,Hukum Perusahaan Indonesia,(Bandung, Citra Aditya Bakti, 2010).

Simanjuntak,Danny, PHK dan Pesangon Karyawan ,(Jakarta, Visi Media,2007).

Soedarjadi,Hak dan Kewajiban Pekerja-Pengusaha,(Yogyakarta,Pustaka Yustisia,2009).

Syaifuddin,M., Hukum Kontrak Memahami Kontrak dalam Perspektif Filsafat, Teori, Dogmatik, dan Praktik Hukum (Seri Pengayan Hukum Perikatan),(Bandung,Mandar Maju,2012,).

29 Hasil wawancara dengan Sinta Kusumantari, Director of Human Resources, tanggal 25 Desember 2019, bertempat di Hotel Sheraton Bali Kuta Resort. 


\section{Jurnal:}

Aisha,Berliana Destrie,"Pemutusan Hubungan Kerja Yang Didasarkan Pada Pelanggaran Perjanjian Kerja Bersama", Jurnal Jurist-Diction Universitas Airlangga 2,No.1,(2019).

Amalia,Apri, dkk, "Analisis Yuridis Perjanjian Kerja Waktu Tertentu Berdasarkan Undang-Undang Ketenagakerjaan dan Hukum Perjanjian”, USU Law Jurnal 5,No. 1(2017).

Eriza,Novi, “Tanggung Jawab Ganti Rugi Atas Pemutusan Kontrak Kerja Sepihak Terhadap Pekerja Oleh PT. Sucofindo Episi Kota Pekanbaru Berdasarkan Undang-Undang Nomor 13 Tahun 2003 Tentang Ketenagakerjaan”, JOM Fakultas Hukum 3, No.2, (2016).

Maulinda,Rizqa,dkk,"Perlindungan Hukum Bagi Pekerja Kontrak Waktu Tertentu Dalam Perjanjian Kerja Pada PT. Indotruck Utama", Kanun Jurnal Ilmu Hukum 18, No. 3 (2016).

Rosita, Ita,T. N. Hamsyah, "Perlindungan Hukum Terhadap Tenaga Kerja Dalam Perjanjian Kerja Waktu Tertentu Pada Perusahaan Garmen", Jurnal Living Law Universitas Djuanda 8, No. 2 (2016).

Shalihah, Fithriatus, "Implementasi Perjanjian Kerja Waktu Tertentu (PKWT) Dalam Hubungan Kerja di Indonesia", Jurnal Selat, Fakultas Hukum Universitas Riau 4, No. 1 (2016).

Sinaga, Niru Anita, "Peranan Asas-Asas Hukum Dalam Perjanjian",Jurnal Binamulia Hukum, Fakultas Hukum Universitas Dirgantara Marsekal Suryadarma 7,(2018).

Suhartoyo, "Perlindungan Hukum Bagi Buruh Dalam Sistem Hukum Ketenagakerjaan Nasional", Administrative Law \& Governance Journal, Universitas Diponegoro 2,No.2,(2019).

Yuniarti, Rahmi, "Efisiensi Pemilihan Alternatif Penyelesaian Sengketa Dalam Penyelesaian Sengketa Waralaba", Fiat Justitia Journal of Law Fakultas Hukum Universitas Lampung 10, No.3 (2016).

\section{Peraturan Perundang-undangan:}

Undang-Undang Nomor 30 Tahun 1999 tentang Alternatif Penyelesaian Sengketa, Tambahan Lembaran Negara Republik Indonesia Nomor 3872.

Undang-Undang Nomor 13 tahun 2003 tentang Ketenagakerjaan, Lembaran Negara Republik Indonesia Tahun 2003 Nomor 39.

Peraturan Perusahaan Sheraton Bali Kuta Resort Tahun 2018-2020.

\section{Internet}

Utilitarianisme, $\quad$ https://business-law.binus.ac.id/2016/06/30/utilitarianisme-dantujuan-perkembangan-hukum-multimedia-diindonesia/\#: :text=Teori\%20utilitarianisme $\% 20 \mathrm{yang} \% 20$ digagas $\% 20 \mathrm{oleh}$,tidak $\% 20 \mathrm{kab}$ ur\%20dan\%20tidak\%20tetap. , diakses bulan Januari 2020. 